\title{
NASDAQ Market Structure and Spread Patterns
}

\author{
Eugene Kandel Leslie M. Marx* \\ W.E. Simon Graduate School \\ of Business Administration \\ University of Rochester \\ Rochester, NY 14627 \\ e-mail: kandel@mail.ssb.rochester.edu \\ marx@mail.ssb.rochester.edu \\ tel: $716-275-4497$
}

October 6, 1995

-We would like to thank Mike Barclay, Bill Christie, Gene Finn, Dean Furbush, Jeff Harris, John Long, Jamie Selway, Paul Schultz, and Bill Schwert for their comments and suggestions. We thank Aditys Kaul for valuable research assistance. 



\begin{abstract}
This paper argues that the standard competitive equilibrium result that prices will be driven down to the level of marginal cost cannot be routinely applied to the Nasdaq market without explicitly taking into account certain institutional features of the market. We show that price competition among a large number of liquidity-providing dealers does not necessarily reduce spreads below the marginal cost of trading plus twice the exogenously set tick size. We also discuss the existing explanations for the phenomenon of the odd-eighths avoidance documented in Christie and Schultz (1994) and provide an alternative explanation based on the concept of focal-point equilibria. The proposed explanation does not rule out the possibility of collusion, but shows that a simple coordination device may allow market makers to select the largest competitive equilibrium spread and thus attain profits similar to those possible with a formal collusive arrangement. We show that a different coordination device may be required for low-priced stocks because of their smaller tick size. Finally, we examine one month of data on Nasdaq quotes to illustrate some of the ideas of the paper.
\end{abstract}




\section{Introduction}

The recent controversy concerning the efficiency of the Nasdaq market sparked by

- Christie and Schultz (1994) and Christie, Harris and Schultz (1994) is centered around their claim that the observed behavior of the Nasdaq market makers cannot be explained by a standard competitive model. They suggest as an alternative that market makers engage in tacit collusion. ${ }^{1}$ A number of papers followed that disputed the existence of collusion among Nasdaq market makers (see e.g. Godek (1995), Grossman et al. (1995), and Kleidon and Willig (1995)). These papers use the standard argument that collusion is implausible in a market with many competitors and relatively free entry because the collusive price cannot be sustained under competitive pressure. Surprisingly, both the proponents and the opponents of the collusion argument use the same notion of competitive equilibrium to advance their claims. Both sides, as well as some of the earlier literature on market microstructure (e.g. Glosten and Milgrom (1985) and Dutta and Madhavan (1995)), rely on the standard concept of competitive equilibrium, which implies that price competition among multiple participants must drive prices (spreads) to the level of marginal cost.

This paper argues that this standard competitive equilibrium result cannot be routinely applied without explicitly taking into account the institutional features of the Nasdaq market, such as the fixed minimal tick size (a quote increment), which is large relative to the prices charged, preferenced trades, the Excess Spread Policy, and the absence of binding limit orders. ${ }^{2}$ The theoretical results reported in this paper suggest that institutional details play a crucial role in the Nasdaq market equilibrium,

\footnotetext{
${ }^{1}$ In the economic, but not necessarily the legal, sense of this word.

${ }^{2}$ Anshuman and Kalay (1994) and Dutta and Madhavan (1994) also consider the implications of discrete prices. Dutta and Madhavan (1994) focus on the impact of trade flow shocks. Huang and Stoll (1995) document that the execution costs are much higher on Nasdaq than on NYSE for a set of comparable firms. Kothare and Laux (1995) document the rise in Nasdaq spreads over a ten-year period.
} 
and must therefore be explicitly modeled.

One of the implications of our model is that in markets such as Nasdaq with a minimum price increment, competition among market makers will not necessarily drive spreads down to the level of marginal cost. This result is quite general: Bertrand competition in any market with discrete prices does not necessarily drive prices below marginal cost plus one price increment. ${ }^{3}$ In the case of a dealer market such as Nasdaq, in which agents choose both a bid and an ask price, we show that competition does not necessarily drive the spread below marginal cost plus two price increments. This implies that price competition among the liquidity-providing dealers does not necessarily reduce spreads below a level equal to the cost of trading plus twice the exogenously set tick size.

When the minimum price increment is one cent, as in most applications, one can disregard the multiplicity of equilibria and for all practical purposes apply the standard result that in a competitive environment price will equal marginal cost. But in many financial markets, including Nasdaq, we observe stocks with a minimum tick size that is $25 \%$ to $100 \%$ of the spread. Because the price discreteness is large relative to the spreads being charged, it cannot be disregarded. One cannot argue that because "large" spreads are observed for some Nasdaq stocks, the market makers are necessarily behaving in a noncompetitive way. One also cannot argue that competitive forces would necessarily make it difficult for market makers to coordinate on spreads that are greater than marginal cost.

The reader should note that this paper only analyzes competition among dealers whose only task is to provide liquidity. The results do not apply to a market where individual investors also compete for order flow via binding limit orders. Thus, the model reflects the characteristics of a Nasdaq-type market, but would have to be modified to accurately model a NYSE-type market.

\footnotetext{
${ }^{3}$ For example, if prices and costs are in increments of $\$ 0.01$, and two firms have the same marginal cost $c$ and zero fixed cost, then one Bertrand equilibrium has both firms charge a price of $c$, but another Bertrand equilibrium has both firms charge a price of $c+0.01$. By reducing its price from $c+0.01$ to $c$, a firm could capture all of the demand but would have zero profit on each unit sold.
} 
Using our results on the multiplicity of equilibria, we suggest an alternative explanation for the empirical phenomenon of odd-eighths avoidance documented by Christie and Schultz (1994). We argue that avoiding odd eighths constitutes a simple coordination device that drives the market to the most preferred equilibrium for the dealers. The coordination device requires neither ongoing communication nor an enforcement mechanism (all actions are optimal even in the short run), since it merely selects one of the possible competitive outcomes. Furthermore, the coordination device achieves roughly the same level of profits as a formal collusive agreement could in an environment with free entry.

Although our data show odd-eighth avoidance similar to that documented in previous studies, for the subsample of stocks with an average price below $\$ 10$, there is little evidence of avoidance of odd eighths; however, the avoidance of odd sixteenths is prevalent. The analysis of this paper shows why one might expect this type of behavior. Stocks with a price below $\$ 10$ generally have a minimum tick size of $\frac{1}{16}$, as opposed to a minimum tick size of $\frac{1}{8}$ for stocks with prices above $\$ 10$. We show that market makers for stocks with a tick size of $\frac{1}{16}$ can benefit from avoiding quotes using odd sixteenths, but that they might not be able to sustain an agreement to avoid quotes that are not even multiples of $\frac{1}{8}$. We show that when the tick size is $\frac{1}{8}$, an agreement to avoid odd eighths never forces the inside spread to be larger than one of the competitive equilibrium spreads. However, when the tick size is $\frac{1}{16}$, an agreement to avoid quotes that are not even multiples of $\frac{1}{8}$ would frequently force the spread to be larger than the largest competitive equilibrium spread.

The determinants of market maker prices and bid-ask spreads has received considerable attention in the literature. Spreads are typically viewed as being determined by inventory holding costs, the cost of trading and settlement, and adverse selection costs. Spreads have been shown to be related to inventory holding costs in Demsetz (1968), Stoll (1978), Amihud and Mendelson (1980), Ho and Stoll (1981, 1983), and Garman (1976). Adverse selection costs are studied by Copeland and Galai (1983), Glosten and Milgrom (1985), and Easley and O'Hara (1987). Papers studying the relative contribution to spreads of inventory costs and adverse selection costs include 
Madhavan and Smidt (1993), Huang and Stoll (1994), and Glosten and Harris (1988).

Our focus is on the determination of spreads in excess of these costs.

In Section 2 we present an overview of the Nasdaq market. We identify the sub-markets for which the market makers' quotes are most relevant and discuss institutional details relevant for these sub-markets. In Section 3 we derive the main result. In Section 4 we argue that odd-eighths avoidance may be an effective coordination device - it yields profits similar to collusion, yet does not require ongoing communication or punishment. In Section 5 we present some empirical evidence from the January 1994 TAQ Database. This paper is not intended to be an empirical study, but our examination of the data provides some test of the ideas presented in the paper and raises some interesting questions. Section 6 concludes the paper and discusses policy implications of our findings. The Appendix A provides some additional details on Nasdaq's Excess Spread Policy and Appendix B contains the details of our regression results.

\section{Market Features}

Every Nasdaq market maker registered for a particular stock is obligated to maintain active bid and ask quotes for that stock at all times. The system automatically calculates the best quotes (the highest bid and the lowest ask), which constitute the reported inside quotes.

The Nasdaq trading system consists of three separate venues through which market makers can execute trades. The first is the traditional telephone call to another market maker, during which a price is negotiated and the trade executed. Second, a market maker can use the Selectnet system to post a sell or a buy order specifying both quantity and price. ${ }^{4}$ These postings expire after a short period of time, and the price is valid only for that order. Although Selectnet orders are anonymous, a trade executed through Selectnet may lead to negotiation on additional trades. ${ }^{5}$ A third

\footnotetext{
${ }^{4}$ A similar order can be posted on the Instinet system, which is not owned by Nasdaq and is open only to institutions with annual transactions of at least $\$ 10$ million.

${ }^{8}$ We have been told that it is a standard practice for a market maker wishing to sell a large
} 
method of executing trades is through the Small Order Execution System (SOES). This system allows a market maker to submit an order of up to 1000 shares (500 for certain stocks), which is then automatically routed to one of the market makers posting the inside quote and executed. Prices quoted by the market makers become the actual transaction prices in the SOES system without any negotiations. SOES trades constituted roughly $3 \%$ of the Nasdaq share volume in 1993 (see Nasdaq Fact Book 1994) and an even lower share of the dollar volume.

As far as the investors are concerned, quoted prices are only relevant for transactions on SOES and for preferenced trades (see Section 2.2). Quotes posted by a particular market maker do not directly affect the prices (or quantities) at which he or she trades on Selectnet (or Instinet) or the negotiated prices for trades executed via telephone.

\subsection{Fixed Minimum Tick Size}

It is a standard practice for stocks traded on Nasdaq (and other exchanges) to have a fixed minimum tick size, the smallest amount by which the quoted price of a stock can be changed. ${ }^{6}$ The custom is that stocks with prices exceeding $\$ 10$ have a minimum tick size of $\frac{1}{8}$, those with prices between $\$ 5$ and $\$ 10$ have a minimum tick size of $\frac{1}{16}$, and the rest have a minimum tick size of $\frac{1}{32}$. Market makers are constrained to post quotes that are integer multiples of the tick size. This feature is crucial for the SOES system, since quotes automatically become prices. Trades executed via the other two routes are not subject to this constraint since negotiated transaction prices may be any integer multiple of $\frac{1}{64}$.

quantity of a stock to first post a small sell order on Selectnet and wait for a response. If another trader wishes to buy the small quantity at the posted price, the system identifies the traders to one another so that the transaction can be completed. Once the identity of the buyer is known, the initiating market maker can then try to negotiate a price for the remainder of the shares he or she wishes to sell.

${ }^{6}$ We were unable to obtain a copy of the official Nasdaq regulation regarding tick sizes. 


\subsection{Preferencing}

"Preferencing" is a practice that allows a broker receiving an order from a customer to forward the order to the market maker of the broker's choice, regardless of that market maker's quoted prices. However, the price at which the trade is executed must be at or better than the currently displayed inside quotes. Two types of market makers benefit from this provision: those with a large retail operations, such as Merrill Lynch or Dean Witter, and wholesalers, who pay brokers for orders forwarded to them for execution. Notice that for preferenced trades, the inside quotes, rather than the individual quotes of the executing market maker, determine the price at which trades are executed. If a market maker receives preferenced trades and is not interested in executing the trades at the current inside price, he or she may pass the transaction to another market maker. Christie and Schultz (1994) and Godek (1995) discuss preferencing in more detail.

\subsection{Excess Spread Policy}

NASD By-Laws (Part V, Paragraph 1819) state:

All quotations entered by a registered market maker must be reasonably related to the prevailing market and within the parameters established by the NASD Board of Governors.

Market makers whose quotations violate the established parameters will be subject to review by committee, and if their spreads are considered unreasonable, they may be subject to disciplinary action.

The rationale for this regulation, called the Excess Spread Policy (ESP), is the belief that all market makers should be required to actively participate in the quotation system. The 1994 Nasdaq Symbol Directory indicates (p.6):

...Nasdaq programs its system to measure the spreads of all market makers.... They must input quotes with spreads no greater than 125 percent of the average spread of the three market makers with the narrowest 
spread in each security listed in Nasdaq.... However, a market maker would not have to quote less than a 0.25 spread in any security. ${ }^{7}$

Whenever a market maker updates his or her quotes for a security, the system verifies whether the market maker's new spread is within the limits of the ESP. If the updated prices violate the policy, an on-screen warning is issued, but the market maker has the ability to override this warning if desired. The penalties for a violation of the ESP are specified in the NASD Sanction Guidelines (1993). The first violation within a 12-month period results in a Letter of Caution. The second, third, and fourth violation lead to fines of $\$ 1,000, \$ 2,000$ and $\$ 3,000$, respectively. Any further violations result in fines between $\$ 5,000$ and $\$ 25,000$ per violation. ${ }^{8}$ The monitoring is performed on a per firm (e.g., Shearson or Goldman Sachs), rather than per dealer, basis so that more than one violation for the entire firm results in a fine. The Appendix shows the limits on individual spreads imposed by the Excess Spread Policy as it was written before July 1993 and after.

We now proceed to analyze the impact of these institutional features on the equilibrium in this market.

\section{The Impact of Competition}

The arguments implicit in the Nasdaq controversy, as well as much of the theoretical literature on the market microstructure, use the notion of Bertrand equilibrium to describe the effect of competition on the spreads in dealer markets (see e.g. Glosten and Milgrom 1985). The basic claim is that the large number of market makers competing for order flow through quotes should drive spreads down to the marginal cost of trading. In this section we show that this conclusion is too strong for markets

\footnotetext{
${ }^{7}$ There is a clarification to this rule, which does allow spreads in excess of $125 \%$. This is because the $125 \%$ is rounded up to the nearest one eighths. Prior to July 1993 the system actually allowed spreads of $200 \%$ of the average of the smallest three spreads.

${ }^{B}$ Although the penalties seem clear-cut as stated, there is some room for the governing board's discretion in assigning them. We were given the impression that it is rare for the board to grant relief from penalties.
} 
with significant price discreteness and without binding limit orders, such as Nasdaq. In particular we show that in such a market, neither Bertrand competition among the existing market makers nor free entry of additional market makers necessarily drives spreads below the level of marginal cost of making the market plus twice the tick size. To illustrate this point, we initially abstract away from many Nasdaq features and construct a model that is similar to the familiar one-shot Bertrand model and is actually biased against our conclusions. This model can be interpreted as a simplified version of the SOES segment of the Nasdaq market. After analyzing this model, we introduce some of the important institutional features and demonstrate that the conclusions of the base model are only reinforced.

\subsection{Fixed Tick Size}

Consider the following setup: define $\Delta$ as the exogenously given tick size and suppose that there are $n-1$ market makers quoting the inside ask price, $A \equiv a \Delta$, and the same number of market makers quoting the inside bid price, $B \equiv b \Delta$, where $a$ and $b$ are positive integers. To eliminate intertemporal strategic considerations, we assume that these prices are constant over time. We further assume that the flow of nonpreferenced trades is known in advance to be $K$ buy orders and $K$ sell orders per period. The marginal trading cost (simply the processing cost per trade since there is no uncertainty) is assumed to be $C \equiv c \Delta$, where $c$ is a non-negative real number.

The $n^{\text {th }}$ market maker can either quote the same inside prices as the other market makers and share the market with them, or quote a lower ask and/or higher bid and capture the entire flow of orders on one or both sides of the market. We account for end-of-the-period inventory levels by assuming that a positive inventory is disposed of at the price of $\left(\frac{a+b}{2}-\varepsilon\right) \Delta$ and purchases to cover short positions are made at the price of $\left(\frac{a+b}{2}+\varepsilon\right) \Delta$, where $\varepsilon$ denotes the premium a market maker may have to pay to zero his or her inventory. ${ }^{9}$ Table 1 presents possible one-period strategies (an ask

\footnotetext{
${ }^{9}$ This assumption captures the ability of the market makers to negotiate transactions inside the spread. The quantity $\varepsilon$ measures relative bargaining power. An alternative method is to compare the profits for a number of periods for strategies that leave market makers with zero inventory. The
} 
and a bid price) and associated one-period profits for the $n^{\text {th }}$ market maker assuming that he or she has no preferenced trades. We do not present the zero-profit strategy of staying out of the market entirely by quoting prices outside the inside spread on both sides. Strategies in the table are the multiples of the tick size $\Delta$, so strategy $a, b$ means the market maker chooses ask price $a \Delta$ and bid price $b \Delta$.

\begin{tabular}{|l|l|}
\hline Strategy & \multicolumn{1}{|c|}{ Profits } \\
\hline 1. $a, b$ & $\frac{\Delta K}{n}(a-b-2 c)$ \\
\hline 2. $a-1, b+1$ & $\Delta K(a-b-2(1+c))$ \\
\hline 3. $a-1, b$ & $\frac{\Delta K}{2 n}[(n+1)(a-b)-2 \varepsilon(n-1)-2 n(1+2 c)]$ \\
\hline 4. $a, b+1$ & $\frac{\Delta K}{2 n}[(n+1)(a-b)-2 \varepsilon(n-1)-2 n(1+2 c)]$ \\
\hline 5. $a+1, b$ & $\frac{\Delta K}{2 n}[a-b-2(\varepsilon+2 c)]$ \\
\hline 6. $a, b-1$ & $\frac{\Delta K}{2 n}[a-b-2(\varepsilon+2 c)]$ \\
\hline 7. $a+1, b+1$ & $\frac{\Delta K}{2}[a-b-2(\varepsilon+1+2 c)]$ \\
\hline 8. $a-1, b-1$ & $\frac{\Delta K}{2}[a-b-2(\varepsilon+1+2 c)]$ \\
\hline
\end{tabular}

\section{Table 1}

As an example of how the profits in Table 1 are calculated, consider strategy 4. Quoting ask and bid prices of $a \Delta$ and $(b+1) \Delta$ generates sales of $\frac{K}{n}$ at price $a \Delta$ and purchases of $K$ at price $(b+1) \Delta$. This leaves the market maker with positive inventory of $K-\frac{K}{n}$, which he or she sells at a price of $\left(\frac{a+b}{2}-\varepsilon\right) \Delta$. Total transactions costs are $2 K C .^{10}$ So the market maker's one-period profits are

$$
\frac{K}{n} a \Delta-K(b+1) \Delta+\left(K-\frac{K}{n}\right)\left(\frac{a+b}{2}-\varepsilon\right) \Delta-2 K C .
$$

This expression can be rewritten as in Table 1.

Table 2 presents the conditions on the parameters such that the $n^{\text {th }}$ market maker does not have an incentive to deviate from strategy 1 to the other possible strategies. In other words, as long as all of these conditions are met, strategy 1 is a Nash equilibrium.

results remain unchanged.

${ }^{10}$ Initial sales of $\frac{K}{n}$ and purchases of $K$ and sale of inventory of $K-\frac{K}{n}$ result in total transactions of $2 K$. 


\begin{tabular}{|c|c|}
\hline Strategy & \multicolumn{1}{|c|}{ Condition } \\
\hline 2 & $a-b<2 c+\frac{2 n}{n-1}$ \\
\hline 3,4 & $a-b<2 c+\frac{2 n}{n-1}+2(c+\varepsilon)$ \\
\hline 5,6 & $a-b>-2 \varepsilon$ \\
\hline 7,8 & $a-b<2 c+\frac{2 n}{n-2}(1+\varepsilon+c)$ \\
\hline
\end{tabular}

Table 2

Provided that $\varepsilon>-c$, as long as $(a-b) \Delta$ is less than or equal to $2 C+2 \Delta \frac{n}{n-1}$, no market maker has an incentive to deviate from strategy 1 to a strategy that reduces the spread (strategies 2, 3, 4, 7, and 8). ${ }^{11}$ If, in addition, the spread is greater than or equal to $2 C$, then profits are non-negative and no market maker has an incentive to deviate from strategy 1 to strategy 5 or 6 . Thus, for $\varepsilon>-c$, ask and bid prices $a \Delta$ and $b \Delta$ constitute a Nash equilibrium if and only if

$$
2 C+2 \Delta \frac{n}{n-1} \geq a \Delta-b \Delta \geq 2 C
$$

Bertrand competition in this model does not imply that spreads are necessarily driven any lower than $2 C+2 \Delta \frac{n}{n-1}$, which is greater than $2 C+2 \Delta$. The amount $2 C$ is the cost associated with buying and selling one share. Thus, Bertrand competition does not imply that spreads will be driven any lower than the marginal cost of trading plus twice the tick size.

This result also means that there are always at least two Nash equilibrium spreads and occasionally more. A spread equal to $\Delta$ times the smallest integer, such that it is greater than or equal to $2 C$, is an equilibrium, and a spread that is one tick size larger than this is also an equilibrium spread. Figure 1 illustrates the dependance of the number of possible equilibria on the magnitude of the trading cost and the number of competitors. Notice that a stock with only two market makers may have up to 5 equilibria, whereas stocks with ten or more market makers generally have 2

\footnotetext{
${ }^{11}$ Following our interpretation of $\varepsilon$ as a premium that must be paid to dispose of inventory, we expect that $\varepsilon \geq 0$, so the condition that $\varepsilon$ be greater than $-c$ is satisfied. Having $\varepsilon<0$ implies that market makers can dispose of inventory at prices better than the midpoint price, something we believe to be unlikely.
} 
equilibria, and only occasionally 3 .

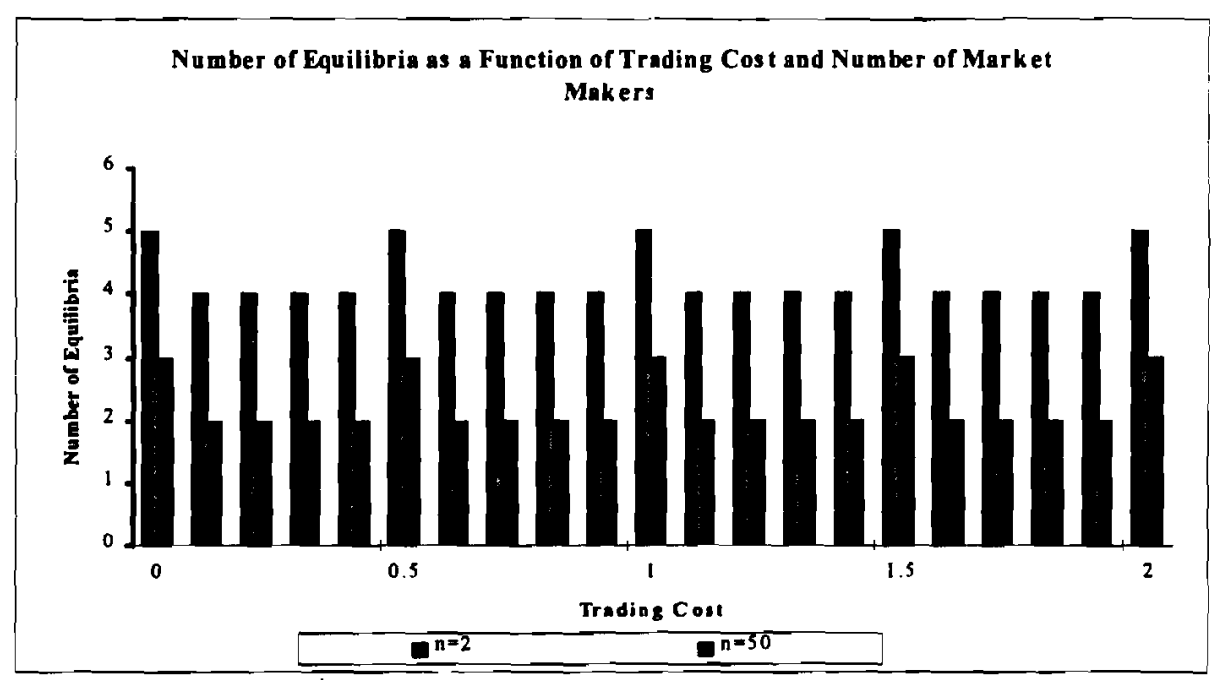

Figure 1:

\subsection{Preferencing}

Suppose now that some of the market makers have access to preferenced order flow. Recall that they must execute these trades at prices that are at or within the inside quotes, regardless of the quotes they post themselves. This means that if such a market maker posts prices better than those of the other market makers on either the ask or the bid side, he or she will reduce profits on his or her own preferenced trades (as well as reducing profits of all the other market makers with preferenced trade flow).

Assuming that the volume of preferenced trades for each market maker is $K_{p}$ shares of buy and sell orders, which is independent of prices. Keeping the rest of the parameters as in the base model, the conditions for the $n^{\text {th }}$ market maker not to deviate from strategy 1 are presented in Table 3 (the strategies are the same as in Table 1). 


\begin{tabular}{|c|l|}
\hline Strategy & \multicolumn{1}{|c|}{ Condition } \\
\hline 2 & $a-b<2 c+\frac{2 n}{n-1}+\frac{2 n K_{p}}{K(n-1)}$ \\
\hline 3,4 & $a-b<2 c+\frac{2 n}{n-1}+2(c+\varepsilon)+\frac{2 n K_{p}}{K(n-1)}$ \\
\hline 5,6 & $a-b>-2 \varepsilon$ \\
\hline 7,8 & $a-b<2 c+\frac{2 n}{n-2}(1+\varepsilon+c)+\frac{2 n K_{p}}{K(n-2)}$ \\
\hline
\end{tabular}

\section{Table 3}

When we consider the impact of preferenced trades, we find that Bertrand competition only implies that inside spreads be less than $2 C+2 \Delta \frac{n}{n-1}+2 \Delta \frac{n K_{p}}{K(n-1)}$, which is strictly greater than $2 C+2 \Delta$ and is increasing in the volume of preferenced trades. This means that a market maker with preferenced trades has even less incentive to reduce the inside spreads and that a wider range of equilibrium spreads exists when all market makers have preferenced order flow. However, if the marginal competitor does not have preferenced order flow, then the equilibrium inside spreads are still determined by the conditions in Table 2 and by equation (1).

\subsection{Asymmetric Information Cost}

The base model can be interpreted as having equally informed investors and dealers. The literature, however, identifies the existence of better informed investors as one of the main determinants of the spread (see Copeland and Galai (1983), Glosten and Milgrom (1985), Easley and O'Hara (1987) and Glosten and Harris (1988)). The dealers must increase spreads to protect themselves against trades with the better informed investors. This is sometimes referred to as the asymmetric information component of the market making cost. We must consider whether the introduction of informed traders reduces the number of possible equilibria. In fact, the discussion below indicates that the introduction of informed traders should only increase the number of equilibria.

The introduction of informed investors into our framework can be modeled as an increase of the market making cost. In an environment with informed traders, if the value of the stock changes, each dealer, adhering to strategy 1 , receives only 
a fraction of any unfavorable trades from the informed traders. If, however, the $n^{\text {th }}$ dealer chooses a lower spread, he or she faces an increase in costs associated with asymmetric information. This is because there is a higher probability that the true value of the security lies outside the narrower spread quoted by the $n^{\text {th }}$ market maker, who therefore faces greater exposure to informed traders. Moreover, being the only market maker posting the inside quote means that all the incoming orders, including those from the informed traders, are routed to the $n^{\text {th }}$ market maker, further increasing his or her risk. These arguments indicate that asymmetric information concerns make deviations toward a smaller inside spread even less attractive than in the base model, implying that the range of the possible equilibrium spreads may in fact increase with the introduction of the informed traders.

\subsection{Inventory Holding Cost}

The other component of the market making costs presented in the literature is due to the risk associated with carrying inventory (see Stoll (1978), Amihud and Mendelson (1980), Ho and Stoll $(1981,1983)$ ). These costs stem from the possibility that the value of the inventory will change in the future. Thus, risk averse dealers demand a premium for taking this risk. If the $n^{\text {th }}$ dealer deviates from the other dealers' quotes, this increases the likelihood of order imbalances, thus increasing the inventory holding cost. In our model, strategies 3-8 result in unbalanced inventories. Under strategy 2 in a stochastic environment, the distribution of possible inventory imbalances would have a higher variance than under strategy 1 . Since inventory holding costs increase with both inventory imbalances and the variance of the imbalances, the attractiveness of deviations from strategy 1 to any of the other strategies is reduced. This implies that the introduction of the inventory holding costs may actually increase the number of equilibria and reinforce our earlier results.

Our model disregards the impact of a potential inventory imbalance at the beginning of the period, which an individual market maker may want to correct by posting a quote inside the spread on the appropriate side. We cannot rule out this possibility for large inventory imbalances, and we believe that such behavior may be observed 
occasionally. However, we do not believe that this is the dominant pattern of behavior. First, large inventory imbalances should be a rarity for a competent dealer in the business of providing liquidity. Second, there are several better venues of correcting inventory imbalances when they do occur. One can post orders or respond to orders posted by others on either Selectnet or Instinet, approach other market makers over the phone, and/or pass incoming preferenced orders to other market makers - all these without altering the quotes in the SOES system and even preserving anonymity in some cases.

\subsection{Excess Spread Policy}

\subsubsection{Asymmetric Equilibria}

The smaller a market maker's spread, the greater attention the market maker must pay to the stock since he or she is more vulnerable to sudden price changes. Since market makers are typically active in over 10 stocks, they are unable to monitor all their stocks all the time. This means that market makers value the option of being able to use individual spreads that are significantly higher than the inside spreads (see Chan, Christie, and Schultz 1995).

As mentioned above, the rationale for the Excess Spread Policy (ESP) is based on the belief that all market makers should be required to actively participate in the quotation system. However, this regulation may have the unexpected effect of putting a lower bound on the individual market makers' spreads. This occurs because ESP sets an upper bound on every market maker's individual spread (determined by the other market makers' spreads), which precludes rapid adjustment of spreads.

For example, if the average of the three lowest individual spreads is equal to $\frac{1}{4}$, then the maximum spread any market maker can quote without violating the excess spread policy is $\frac{3}{8} \cdot{ }^{12}$ By quoting spreads of $\frac{1}{4}$, three market makers can effectively hold all other market makers to spreads of $\frac{3}{8}$ or less. Thus, market makers may be hesitant to reduce spreads temporarily because they may find themselves "trapped" at lower

\footnotetext{
${ }^{12} 125 \%$ of $\frac{1}{4}$ is 0.3125 , which is rounded up to $\frac{3}{8}$.
} 
spreads if other market makers match their prices. Moreover, if market makers avoid odd eighths, i.e. the effective price increment is $\frac{1}{4}$, then the ESP implies that once three market makers have spreads of $\frac{1}{4}\left(\frac{1}{2}\right)$ or below, all market makers are forced to use spreads of $\frac{1}{4}\left(\frac{1}{2}\right)$ or below.

If the ESP gives market makers the incentive to keep individual spreads permanently wide, it may increase the attractiveness of posting asymmetric prices. For example, suppose that due to the ESP all $n$ market makers are reluctant to post individual spreads below $s \Delta .^{13}$ Following our earlier example, suppose that $n-1$ market makers are quoting the ask price $a \Delta$ and the bid price $(a-s) \Delta$ and that the volume of buy and sell orders is $K$. The only way the $n^{\text {th }}$ market maker can reduce the inside spread without posting a spread less than $s \Delta$ is to post one price that is outside the quotes of the other market makers and one that is inside. For example, the $n^{\text {th }}$ market maker could post an ask price of $a^{\prime} \Delta$ and a bid price of $\left(a^{\prime}-s\right) \Delta$.

The simplest way to evaluate the attractiveness of this strategy is to consider a two-period model and compare the profits for this strategy with profits for the strategy of posting ask and bid prices of $a \Delta$ (the inside ask price) and $(a-s) \Delta$. For simplicity, we disregard intertemporal strategic considerations. The two-period profit from adhering to everyone else's strategy is $\frac{2 \Delta K}{n}(s-2 c)$. But deviating from this strategy by posting prices of $(a-1) \Delta,(a-1-s) \Delta$ in one period and $(a+$ 1) $\Delta,(a+1-s) \Delta$ in the following period yields profits of $\Delta K(s-2-2 c)$. Therefore, the symmetric equilibrium cannot be sustained if $s-2 c>\frac{2 n}{n-2}$.

To illustrate this result, consider a stock with a tick size of $\frac{1}{8}$ for which the marginal cost of making market is small. If market makers are reluctant to quote individual spreads less than $\frac{1}{2}$ due to the ESP and the number of market makers is sufficiently high, then the symmetric equilibrium cannot be sustained. Notice that this asymmetric equilibrium is not driven by asymmetry in information or inventory levels, but solely by the regulatory environment.

\footnotetext{
${ }^{13}$ This assumption requires that the cost of an ESP violation be sufficiently high, which seems to be consistent with the evidence in Chan, Christie and Schultz (1995).
} 


\subsubsection{Equilibrium Spreads}

Suppose that due to the considerations mentioned above, market makers are unwilling to post individual spreads below certain minimum, $s \Delta$, assumed to be greater than the current inside spread, because doing so would constrain their ability to increase spreads in the future. In this case, in each period a market maker can post a price on either the ask side of the inside spread or the bid side, but not both. We need to show that this feature does not reverse the results derived in Section 3. As in the previous analysis, we consider all the strategies from which an individual market maker may choose, but now we allow two periods of trading. Since two-period strategies that result in nonzero inventories after two periods can be shown to be inferior to one of the strategies that results in zero inventory (assuming that inventories are eliminated after period 2 by buying shares at a price of $\left(\frac{a+b}{2}+\varepsilon\right) \Delta$ or selling shares at a price of $\left(\frac{a+b}{2}-\varepsilon\right) \Delta$, where $\left.\varepsilon>-c\right)$, we only consider feasible two-period strategies that result in zero inventory at the end of two periods. Table 4 presents these strategies and the corresponding two-period profits. In the table $a \Delta$ denotes the inside ask and $b \Delta$ denotes the inside bid, $s \Delta$ denotes the lower bound on the spread that an individual market maker is willing to post, and it is assumed that $a-b<s$.

\begin{tabular}{|l|l|c|}
\hline \multicolumn{1}{|c|}{$\begin{array}{c}\text { Strategy } \\
\text { in Period 1 }\end{array}$} & \multicolumn{1}{c|}{$\begin{array}{c}\text { Strategy } \\
\text { in Period 2 }\end{array}$} & Profits \\
\hline 1. $b+s, b$ & $a, a-s$ & $\frac{\Delta K}{n}[a-b-2 c]$ \\
\hline 2. $a, a-s$ & $b+s, b$ & $\frac{\Delta K}{n}[a-b-2 c]$ \\
\hline 3. $b+s+1, b+1$ & $a-1, a-s-1$ & $\Delta K[a-b-2 c-2]$ \\
\hline 4. $a-1, a-s-1$ & $b+s+1, b+1$ & $\Delta K[a-b-2 c-2]$ \\
\hline
\end{tabular}

Table 4

Strategies 1 and 2 result in an inside spread of $(a-b) \Delta$. Strategies 3 and 4 result in a smaller inside spread. The deviations defined by strategies 3 and 4 are dominated by strategies 1 and 2 as long as $2 c+2 \frac{n}{n-1} \geq a-b$, which is the same condition as derived in Section 3.1. This indicates that even when the effects of the ESP are considered, there are multiple equilibrium spreads. Again, competition does 
not necessarily reduce the inside spread below two ticks above marginal cost.

\section{Odd-Eighths Avoidance}

\subsection{Existing Hypotheses}

Christie and Schultz (1994) document that in 1991, market makers for 70 out of the 100 most actively traded stocks on Nasdaq systematically avoided using quotes ending with odd eighths. While Harris (1991) shows that NYSE specialists also tend to favor even-eighths quotes, using them roughly $55-60 \%$ of the time, the Nasdaq pattern is clearly of a different magnitude. A subsequent study by Grossman et al. (1995) shows that some degree of price clustering is observed in other dealer markets as well, but on a smaller magnitude than on Nasdaq.

Below we discuss the two main hypotheses that have been offered to explain the observed avoidance of odd eighths. These arguments are presented in Christie and Schultz (1994), Godek (1995), Grossman et al.(1995) and Kleidon and Willig (1995). ${ }^{14}$

1. Cost of Negotiations and Convenience. First suggested in Harris (1991), one explanation for the avoidance of odd eighths is that clustered prices allow market makers to economize on negotiation time since coarse price increments reduce the time required to arrive at a mutually agreeable price. Grossman et al. (1995) present evidence that real estate prices are usually quoted in increments of $\$ 1,000$ and that clustering occurs in many other dealer markets. In the context of Nasdaq, the argument that clustering economizes on negotiations time can only be applied to transaction prices for stocks traded through

\footnotetext{
${ }^{14} \mathrm{~A}$ third argument advanced by Grossman et al. (1995) is that changing a quote by $\frac{1}{4}$ is more convenient and takes less time than changing it by $\frac{1}{8}$, providing another reason for clustering. However, the terminal on which market makers input quotes is set up in such a way that pushing one button automatically moves both the bid and the ask by $\frac{1}{8}$ in the same direction. Moving the quotes by $\frac{1}{4}$ requires pushing the button twice. This feature may explain the abundance of short-lived quotes ending with an odd eighth for stocks in which odd eighths are generally avoided - these may be just entry errors that are quickly corrected.
} 
Selectnet or over the telephone since these are the only cases in which prices are actually negotiated. However, the evidence suggests that transaction prices from Selectnet and phone trades are much finer than the quotes, frequently ending in odd $\frac{1}{32}$ or $\frac{1}{64}$ multiples.

One might argue that quotes are only relevant for the small transactions executed automatically on the SOES system and that small differences in prices are not important for such small transactions. Christie and Schultz (1994) show that for 30 stocks that regularly used odd-eighths quotes, the distribution of transaction prices for trades of over 1,000 shares is essentially indistinguishable from the distribution of transactions prices for trades of under 1,000 shares. This suggests that economizing on negotiations time is not the primary reason for avoiding odd eighths. On the other hand, for stocks that avoided odd eighths, prices for small transactions used even eighths almost exclusively, while larger transactions used finer price increments.

2. Collusion. Christie and Schultz (1994) as well as Kleidon and Willig (1995) find that one of the most significant variables in predicting odd-eighths avoidance tomorrow is whether odd eighths are used today. The former interpret this fact, in combination with other findings, as evidence of a tacit collusion. ${ }^{15}$ They argue that in a competitive equilibrium prices should be close to marginal cost, which is not the case in their sample, and, furthermore, that there is no reason marginal costs should only have values ending with even eighths.

Grossman et al. (1995), and Kleidon and Willig (1995) dispute the existence of overt collusion by arguing that competition from the numerous existing market makers, as well as relatively free entry, make it implausible since a collusive price could not be sustained against competitive pressures. Kleidon and Willig (1995) attribute the documented persistence of odd-eighths avoidance to the economic fundamentals.

\footnotetext{
${ }^{15}$ By referring to tacit collusion, the authors seem to refer to Tirole's (1988) (p. 207) definition of it stating, "...the collusion is only apparent; it results from optimal noncooperative behavior."
} 
Our model incorporates the institutional features of the Nasdaq market and derives the following results: for any number of competing market makers, (i) there exist at least two equilibria, and (ii) there exists an equilibrium in which the inside spread is greater than or equal to the marginal cost of trading plus twice the tick size. In other words, no matter how many market makers engage in Bertrand price competition, spreads need not be driven below the level of marginal cost plus twice the tick size. ${ }^{16}$ The implications of this result for the sample of stocks used in Christie and Schultz (1994) (all quoted on a $\frac{1}{8}$ tick size) are illustrated in Figure 2, which depicts the equilibrium spreads for various values of trading cost assuming 50 dealers. As one can see, for stocks with a low marginal cost of making market (liquid, non-volatile stocks), the equilibria include inside spreads of $\$ 0.125$ and $\$ 0.25$. Stocks with higher marginal costs have higher equilibrium inside spreads.

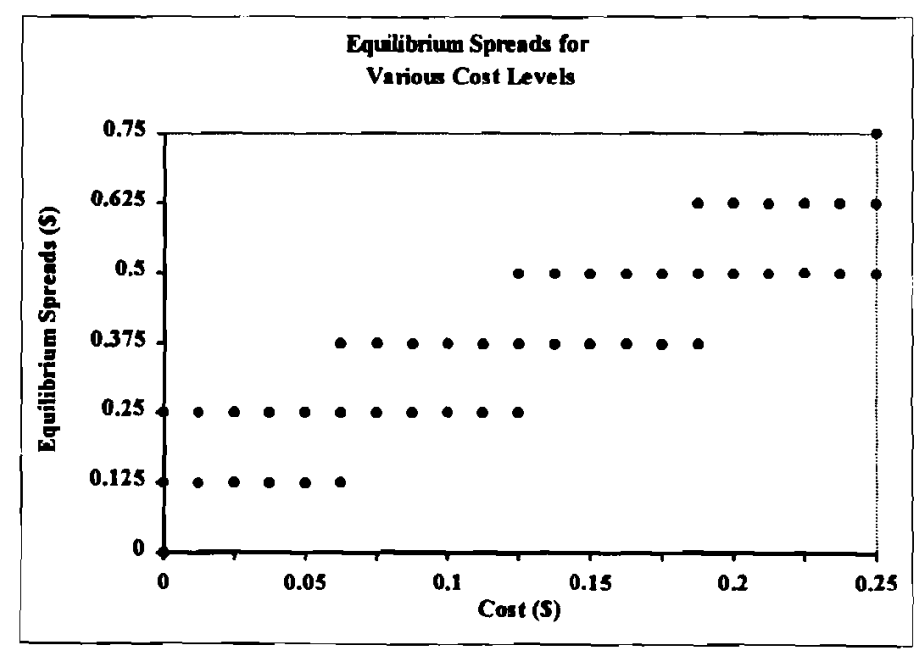

Figure 2:

Given this result, the documented evidence in Christie and Schultz (1994) provides less reason for alarm since large spreads need not imply collusion. Even in a competitive environment prices may be significantly larger than marginal costs.

\footnotetext{
${ }^{16}$ With only two active market makers, spreads need not be driven below the level of marginal cost plus four times the tick size.
} 
On the other hand, the dismissal of the collusion hypothesis is not immediate either. Collusive agreements may still exist, but our results also suggest an alternative explanation for odd-eighths avoidance, which is presented below.

\subsection{Odd Eighths Avoidance as a Coordination Device}

The argument presented in this section is based on the idea that when a game has several possible equilibria, one of which is strictly preferred by all the players, the players are likely to use norms, conventions, or other coordination devices to focus on the preferred equilibrium. The chosen equilibrium is referred to as a focal-point equilibrium.

Since Nasdaq market makers interact over a long period of time, a coordinating convention is likely to be established and thus make further communications unnecessary. ${ }^{17}$ If market makers coordinate on one of the Nash equilibria of the game, then no punishments are necessary to sustain this equilibrium since it is in every player's interest to adhere to his or her strategy. The difference between this scenario and collusion is that in a collusive arrangement a punishment mechanism is essential to prevent deviations. Using a coordination device simply allows market makers to select a particular one of the possible competitive outcomes.

The remainder of this section describes the rationale for using the avoidance of odd eighths as a coordination device and shows that market makers may be able to obtain roughly the same level of profits using this coordination device as they would under a more formal collusive agreement. Since the results on the avoidance of odd eighths differ for stocks with a tick size of $\frac{1}{8}$ and those with a tick size of $\frac{1}{16}$, these cases will be considered separately.

Our analysis shows why market makers might want to restrict the quotes they use so that inside spreads generated by those quotes would always be an even number of ticks; however, this could be achieved by restricting individual quotes to either

\footnotetext{
${ }^{17}$ We have been told that there in fact exists a convention among the market makers that "...you just do not move prices of high-priced stocks by less than a quarter...." The question remains as to what "high-priced" means.
} 
even-eighth quotes or odd-eighth quotes. Our analysis does not address why market makers might restrict themselves to quotes ending in even eighths rather than quotes ending in odd eighths, although that is what the data seem to indicate. We can only say that given the choice, people seem to be more comfortable with the quotes ending in even eighths.

\subsubsection{Odd Eighths Avoidance with a Tick Size of One Eighth}

Consider a stock with a tick size of $\frac{1}{8}$ for which there is a low marginal cost of making market. We have shown earlier that for such a stock there generally exist two Nash equilibria, one with a spread of $\frac{1}{8}$ and one with a spread of $\frac{1}{4}$ (see Figure 2). We compare two modes of behavior, one in which market makers use the full range of price increments and another in which they only quote prices with even eights.

If all the market makers use all the quotes available to them, the spread is expected to be either $\frac{1}{8}$ or $\frac{1}{4}$. In reality price levels and inside spreads move all the time, thus we have to consider the transitional pattern of prices. A transition from an inside spread of $\frac{1}{8}$ at one level of prices to higher or lower prices must involve a move to an inside spread of $\frac{1}{4}$. Since a spread of $\frac{1}{4}$ is an equilibrium as well, it may persist until the next change in prices. A transition from an inside spread of $\frac{1}{4}$ at one level of prices to higher or lower prices may involve a move to an inside spread of $\frac{1}{8}$ or to an inside spread of $\frac{3}{8}$. For stocks with a low marginal cost of making market, the former is an equilibrium, but the latter is not. Thus, if the inside spread moves to $\frac{3}{8}$ during a transition, we expect it to return quickly to the $\frac{1}{4}$ level. Moreover, a price transition using the lower spread is much more likely than a price transition using the higher spread since it requires the action of only one market maker. A price transition using a higher spread can be accomplished only if all market makers posting the inside quote on one side of the market adjust that quote while the other side of the inside quote remains fixed.

To quantify this feature, denote the probability of price-moving information arriving in any period by $\theta$ and the conditional probability of this information reaching any single market maker by $\gamma$. If there are $N_{a}$ market makers posting the inside ask 
quote and there are $N_{b}$ different market makers posting the inside bid quote, then the probability of a price transition using a higher spread conditional on the arrival of price-increasing information is

$$
(1-\gamma)^{N_{b}} \gamma^{N_{a}}
$$

Figure 3 illustrates the pattern of spreads generated by a simulation using $\theta=0.1$, $\gamma=0.5$, and $N_{a}=N_{b}$, which vary randomly in the range of 1 to 10 per period. ${ }^{18}$ Clearly transitions using inside spreads of $\frac{1}{8}$ are more prevalent than transitions using inside spreads of $\frac{3}{8}$. The average spread is close to the midpoint between $\frac{1}{4}$ and $\frac{1}{8}$.

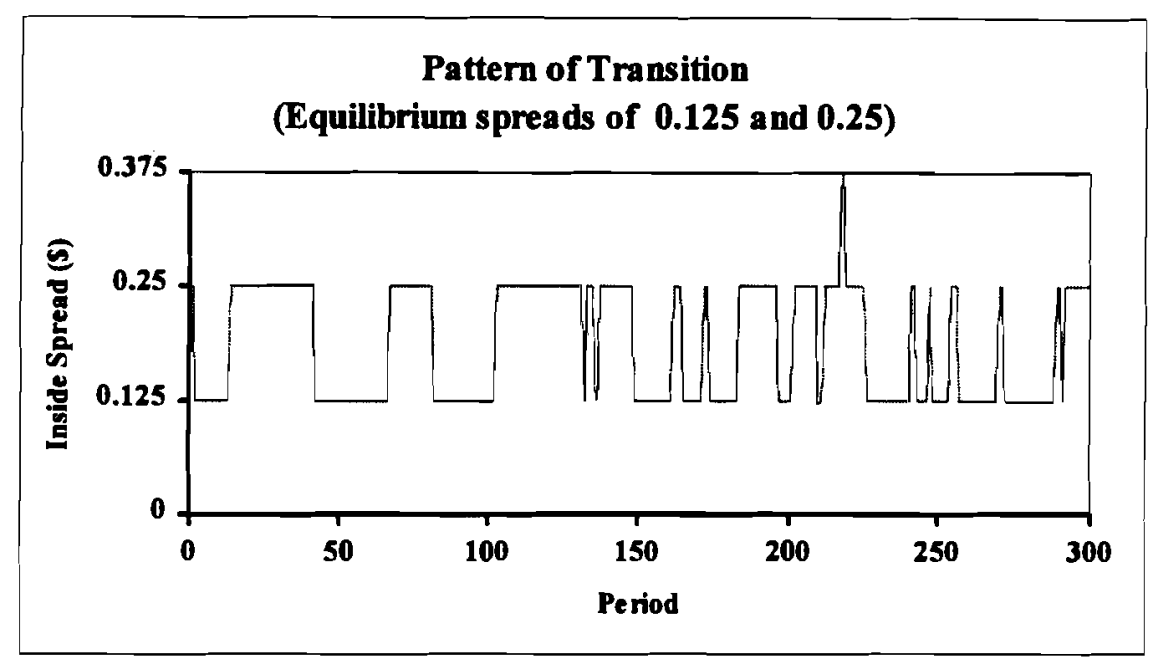

Figure 3:

Suppose now that there is a convention that for stocks with a tick size of $\frac{1}{8}$, market makers avoid using quotes ending with odd-eighths multiples. The most trivial implication is that this convention eliminates the possibility of having an inside spread of $\frac{1}{8}$, leaving $\frac{1}{4}$ as the only possible equilibrium spread. As long as the stock price is not moving, there is no incentive for market makers to deviate, so no punishment mechanism is necessary. The convention of avoiding odd eighths merely acts as a coordination device and the profits of the market makers increase by $33 \%$ relative to

\footnotetext{
${ }^{18}$ These parameters are chosen arbitrarily for expositional purposes.
} 
the case of using odd-eighths quotes. The avoidance of odd eighths may have an even bigger impact on profits during price transitions. When market makers avoid odd eighths, we would expect to observe prolonged spells of inside spreads of $\frac{1}{4}$ interrupted by transitory periods with spreads of $\frac{1}{2} \cdot{ }^{19}$ The average spread would be expected to be somewhat greater than $\frac{1}{4}$. As a result of avoiding odd eighths, we expect the average inside spread to increase by at least $33 \%$ and potentially as much as $50 \%$. If the marginal cost is $\$ 0.05$, this implies an increase in profits of $55 \%$.

In an environment with free entry, a collusive agreement that fixes inside spreads above $\frac{1}{4}$ may give a potential entrant the incentive to enter with a lower spread, disrupting the ability of the colluding market makers to maintain a high spread. Unless the collusive agreement includes all current and potential market makers, inside spreads much above $\frac{1}{4}$ cannot be maintained. On the other hand, a collusive agreement fixing $\frac{1}{4}$ as the lower bound on the inside spread could be maintained because entrants would not have any incentive to use a strictly lower spread. But as we have shown, profits close to those generated by such a collusive agreement can be achieved without collusion.

When costs are such that the two equilibrium spreads are $\frac{1}{4}$ and $\frac{3}{8}$, then it may or may not be in the market makers' best interest to avoid odd eighths. If the full range of quotes is used, we would expect to observe spreads of $\frac{1}{4}$ and $\frac{3}{8}$ most of the time. From a spread of $\frac{1}{4}$, price transitions may move through either $\frac{1}{8}$ or $\frac{3}{8}$ spreads. We expect transitions to an inside spread of $\frac{1}{8}$ to be brief since this is not an equilibrium spread. From a spread of $\frac{3}{8}$, price transitions may move through a spread of $\frac{1}{4}$ or $\frac{1}{2}$. As noted before, price transitions through the lower spread are more likely since they do not require the coordinated movement of all market makers on one side of the market. Figure 4 illustrates the pattern of spreads generated by a simulation using the same parameter values as before but for equilibrium spreads of $\frac{1}{4}$ and $\frac{3}{8}$. The average spread for this type of stock will be some value close to $\frac{1}{4}$; the average spread is likely to be smaller than $\frac{1}{4}$ but could exceed $\frac{1}{4}$.

\footnotetext{
${ }^{19}$ The $\frac{1}{2}$ spread may be an equilibrium as well, in which case we would observe comparable proportions of the two spreads.
} 


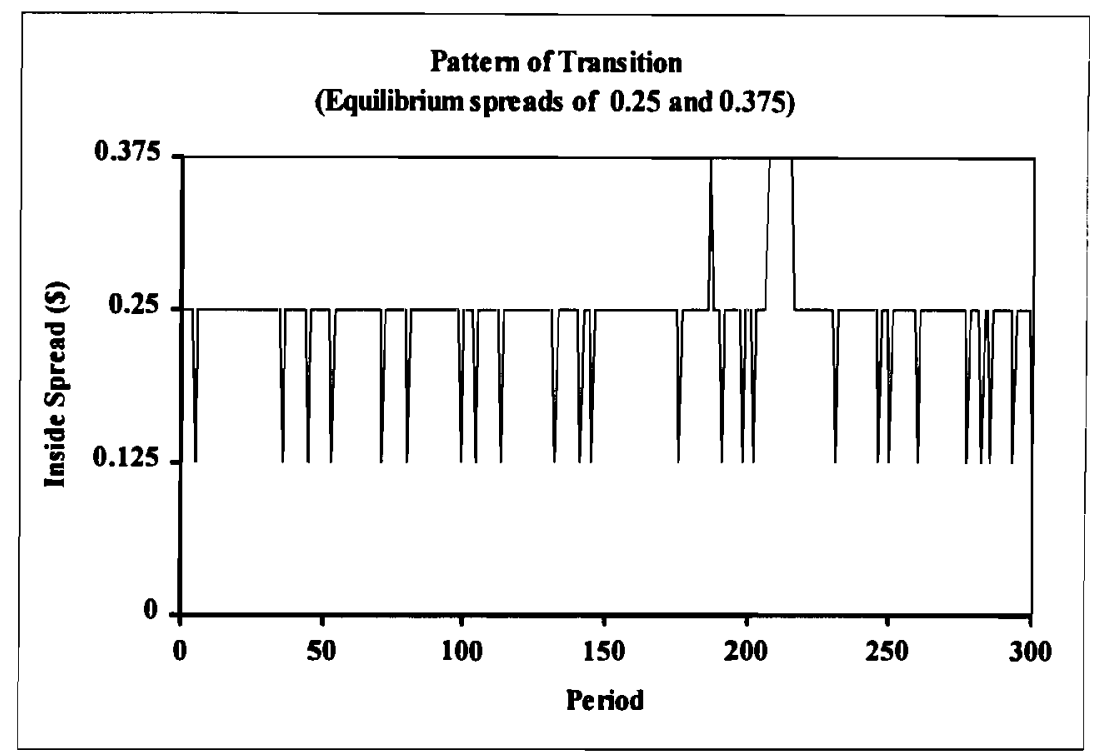

Figure 4:

In this environment, if the market makers avoided odd eighths, the only equilibrium spread would be $\frac{1}{4}$ and price transitions would occur through a spread of $\frac{1}{2}$. This coordination would result in average spreads somewhat greater than $\frac{1}{4}$. It is not clear whether the coordination would result in spreads that are higher or lower on average than those achieved without coordination, but the simulation indicates that the difference would not be large. In certain cases, an increase in costs may cause the convention of avoiding odd eighths to be dropped, which may lead to a surprising reduction in the inside spreads. This may help explain why we observe in the data what appear to be occasional breakdowns in the coordination device. On the other hand, if the change in costs is temporary, breaking the convention may not be optimal since it may take time to reestablish.

If costs are such that the two equilibrium spreads are $\frac{3}{8}$ and $\frac{1}{2}$, then once again avoiding odd eighths is clearly beneficial to the market makers.

If market makers use the avoidance of odd eighths as a device for coordinating on the preferred equilibrium spread, then we would expect to observe higher spreads for that stock than we would otherwise. In Section 5 we present evidence on how the 
avoidance of odd eighths affects spreads.

\subsubsection{Odd Eighths Avoidance with a Tick Size of One Sixteenth}

The theory implies that if the cost of making the market is low, equilibrium spreads for stocks with a minimum tick size of $\frac{1}{16}$ will be $\frac{1}{16}$ and $\frac{1}{8}$, as opposed to $\frac{1}{8}$ and $\frac{1}{4}$ for a stock with similar costs but a minimum tick size of $\frac{1}{8}$. Consider the impact of avoiding quotes that are not even multiples of $\frac{1}{8}$ if the tick size is $\frac{1}{16}$. With avoidance of all but even eighth quotes, the inside spread will be at least $\frac{1}{4}$, at least two tick sizes larger than the largest equilibrium spread. Clearly, such spreads cannot be maintained in a competitive environment, so we would not expect to observe this type of behavior for stocks with low market making costs. On the other hand, avoiding odd sixteenths has the same effect as avoiding odd eighths has for stocks with a tick size of $\frac{1}{8}$. Thus, if market makers are able to coordinate their actions, we would expect to observe avoidance of odd sixteenths in stocks with a tick size of $\frac{1}{16}$.

The results of Section 3 indicate that, all else the same, we expect to see higher spreads for stocks with a larger tick size. The analysis of this section, indicates that, in addition, we expect a higher occurrence of odd-eighths avoidance in stocks with a larger tick size. Because stocks priced above $\$ 10$ have the larger tick size, we expect to observe larger spreads for stocks with prices above $\$ 10$ versus below $\$ 10$.

Comparing stocks with prices that are of different orders of magnitude one would expect there to be many factors contributing to the difference in the observed price increments. Quotes for a stock priced around $\$ 1,000$ might only be in even dollar amounts simply because smaller price adjustments are viewed as insignificant. However, differences in the avoidance of odd-eighths for stocks slightly below $\$ 10$ and slightly above $\$ 10$ cannot be explained in this way.

\section{Empirical Evidence}

The model and the subsequent analysis lead to several empirical implications. While this paper is predominantly a theoretical analysis, we have attempted to construct 
some simple tests of the model's implications with data on 345 Nasdaq-traded stocks from the January 1994 TAQ Database. ${ }^{20}$ Additional empirical work is under way. The results of our initial investigation are presented below.

\subsection{Persistence of Two Equilibrium Spreads}

The arguments presented in Section 3 imply that for stocks with low trading costs there typically exist two equilibrium spreads. We expect the frequency of observing these two equilibrium spreads to be high, interrupted only by occasional transitions through non-equilibrium spreads. Recall that multiple market makers typically post the ask and bid prices, price changes will typically involve an expansion or contraction of the inside spread, preventing the use of only one spread over time. However, if costs are changing over time or if there are a small number of market makers, then we may observe a larger number of different spreads.

For the stocks in our sample, we calculated the percentage of time that each possible spread was in effect for each stock during the 21 trading days. We then calculated the percentage of total trading time the two highest frequency spreads for each stock were in effect. The results are displayed in Figure 5. Only fifteen percent of the stocks in the sample had a percentage of time spent at the two most frequent spreads of less than $75 \%$. Sixty-one percent of the stocks spent more than $90 \%$ of the trading time with a spread equal to one of the stock's two most frequently used spreads; $20 \%$ of the stocks were quoted with only two spreads for the entire month.

More than $93 \%$ of the stocks in our sample have one of the following pairs as their two most frequently used spreads: $\left(\frac{1}{8}, \frac{1}{4}\right)(19 \%),\left(\frac{1}{4}, \frac{3}{8}\right)(13 \%),\left(\frac{1}{4}, \frac{1}{2}\right)(27 \%)$, and $\left(\frac{1}{2}, \frac{3}{4}\right)(34 \%)$.

We explain the need for the use of at least two spreads by noting that price

\footnotetext{
${ }^{20}$ We identified all the stocks that were priced between $\$ 7$ and $\$ 12$ or between $\$ 16$ and $\$ 40$ on January 5, 1994. This choice of stocks was made because we wanted to have one set of stocks that frequently traded with a tick size of $\frac{1}{16}$ (but not a tick size of $\frac{1}{32}$ ) and another that only used a tick size of $\frac{1}{8}$. We then chose the upper quintile in terms of January 5, 1995 volume for each group. The result was 345 stocks. We performed most of our analyses on another sample as well, and the results were essentially the same.
} 


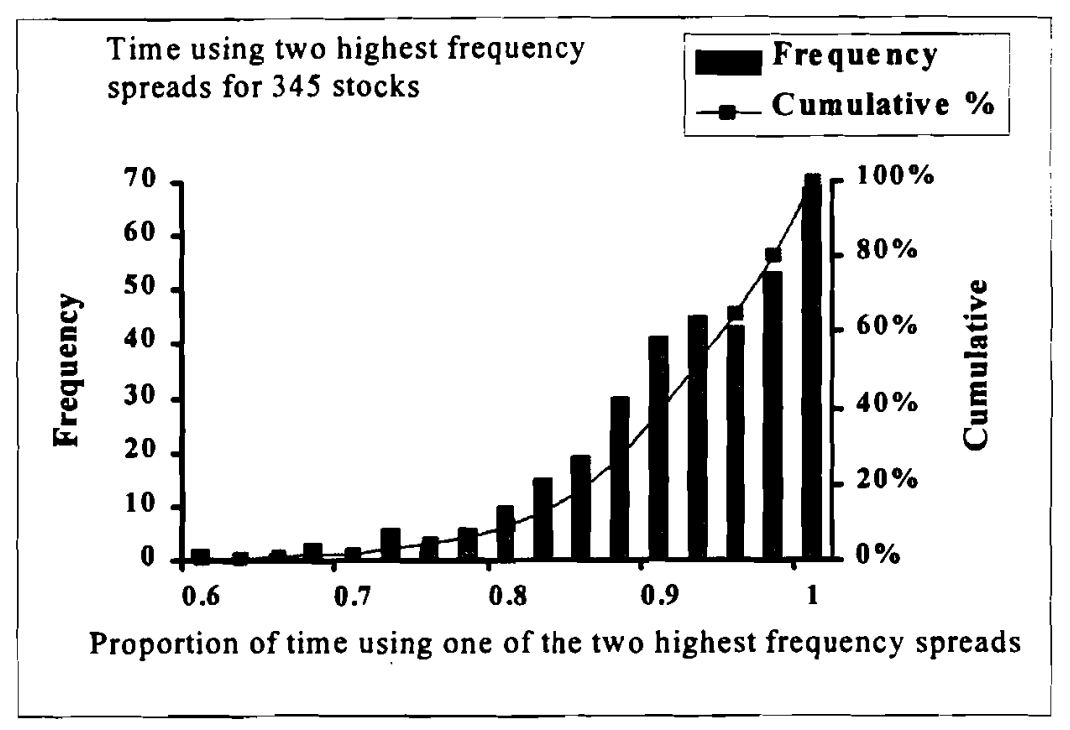

Figure 5:

transitions must involve at least the temporary use of a different spread. For stocks that use two spreads almost exclusively, there are two possible scenarios that would generate the movement between the two spreads. First, the alternation in spreads may reflect price changes: ask moves up then bid moves up (or vice versa) or bid moves down then ask moves down (or vice versa). Second, the alternation in spreads may reflect movement in either the ask or the bid while the other price remains fixed. Of course, for stocks that use more that two spreads, a wider variety of scenarios are possible. In order to get an idea what type of behavior is most responsible for generating changes in the spreads, we examined the 104 stocks in the sample that use one of only two spreads more than $99 \%$ of the time. First, we ask what proportion of the pairs of quotes in the sample have the ask moving up and then the bid moving up or have the bid moving down followed by the ask moving down. That is, we ask what proportion of the pairs of quotes have either the ask leading upward movement in the price or the bid leading downward movement in the price. We find that $34 \%$ of the pairs of quotes have the ask leading upward movement in price and $30 \%$ of the pairs of quotes have the bid leading downward movement in price. So $64 \%$ of the 
pairs of quotes can be viewed as one of these two types. Because these are stocks that primarily use one of only two spreads, almost all of the other $36 \%$ of the pairs of quotes involve either the bid or ask alternating between two values while the other price remains fixed.

\subsection{Avoidance of Odd Eighths}

We begin this section by presenting some evidence on odd-eighth avoidance in our data. Figure 6 shows the histogram for the proportion of time odd-eighth quotes were used for the different stocks in the sample. This histogram closely resembles one produced by Christie and Schultz (1994). ${ }^{21}$

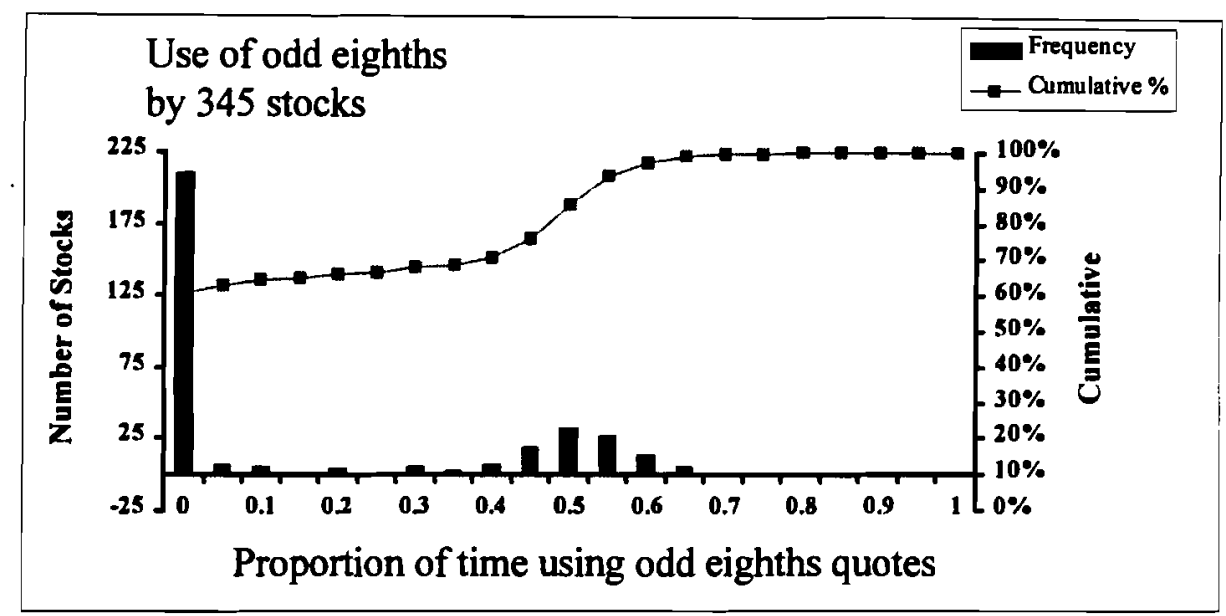

Figure 6:

As stated in Section 4.2.2, our analysis implies that there should be substantially less avoidance of odd eighths for stocks with a minimum tick size of $\frac{1}{16}$, which are those stocks traded at prices below $\$ 10$. Other factors may be contributing to this effect, but as you can see in Figure 7, the histogram for odd-eighths usage is significantly different across the $\$ 10$ threshold.

\footnotetext{
${ }^{21}$ Christie and Schultz (1994) use the proportion of quotes rather than the proportion of time. We feel it is more appropriate to use the proportion of time because the time for which quotes are in effect varies significantly; however, all the reported results are essentially the same.
} 

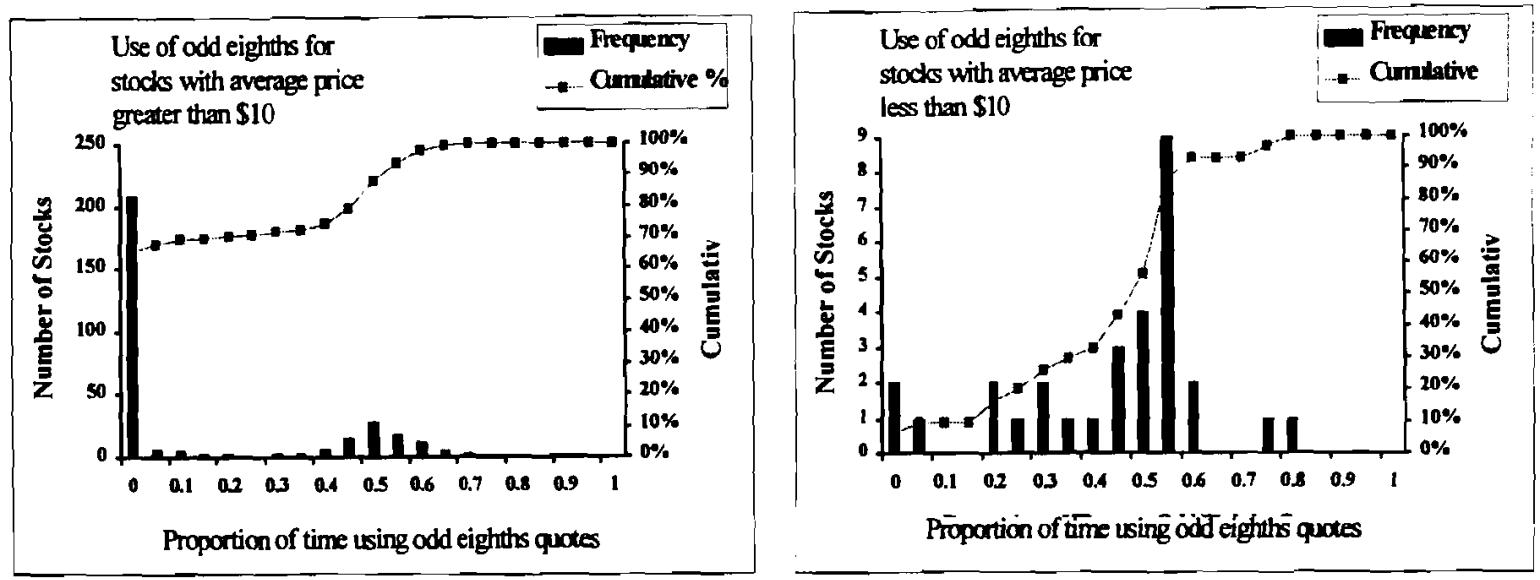

Figure 7:

For stocks with an average (time weighted) price greater than $\$ 10$, the histogram is essentially the same as for the entire sample. About $24 \%$ of the stocks use odd eighths $40-60 \%$ of the time, while $70 \%$ of the stocks rarely use odd eighths. ${ }^{22}$ However, for stocks with an average (time weighted) price below $\$ 10$, the picture is quite different. About $60 \%$ of the stocks use odd eighths $40-60 \%$ of the time, while only $10 \%$ of the stocks in this price range rarely use odd eighths. However, fewer than $10 \%$ of the low-priced stocks use odd sixteenths, i.e. one can claim that market makers in stocks priced under $\$ 10$ avoid odd sixteenths. Both the avoidance of odd sixteenths and the use of odd eighths in these stocks are consistent with the model.

The percent of time that the inside quote uses add eighths for stocks in various price ranges is given in Table 5. This data reinforces the results depicted in Figure 7.

\footnotetext{
${ }^{22} \mathrm{By}$ rarely using odd eighths, we mean that they are used less than $10 \%$ of the time.
} 


\begin{tabular}{|c|c|c|c|}
\hline $\begin{array}{c}\text { Average time- } \\
\text { weighted } \\
\text { price range } \\
\text { (num obs) }\end{array}$ & $\begin{array}{c}\text { Percent of } \\
\text { time using } \\
\text { odd-eighth } \\
\text { quotes (sd) }\end{array}$ & $\begin{array}{c}\text { Average } \\
\text { time- } \\
\text { weighted } \\
\text { spread (sd) }\end{array}$ & $\begin{array}{c}\text { Average } \\
\text { time- } \\
\text { weighted } \\
\text { price (sd) }\end{array}$ \\
\hline$<\$ 10(32)$ & $0.41(0.21)$ & $0.27(0.10)$ & $8.91(0.81)$ \\
\hline$\$ 10-\$ 20(92)$ & $0.23(0.25)$ & $0.40(0.16)$ & $15.61(3.53)$ \\
\hline$\$ 20-\$ 30(146)$ & $0.11(0.20)$ & $0.47(0.17)$ & $24.80(2.83)$ \\
\hline$>\$ 30(75)$ & $0.10(0.20)$ & $0.49(0.16)$ & $34.68(3.27)$ \\
\hline
\end{tabular}

Table 5

One may argue that the above evidence can be explained by the differences in the stock attributes. To test this we regress the percent of time a stock has an inside quote using an odd eighth on the number of quotes during the period, the standard deviation of price, and the average price. We find distinctly different relationships for stocks with prices above $\$ 10$ versus stocks with prices below $\$ 10 .^{23}$ Regression results are reported in Appendix B. Even after controlling for other variables, the proportion of odd-eighths usage is significantly higher in the sample of stocks with a tick size of $\frac{1}{16}$, as predicted by the model. Also, while the price levels are quite significant in explaining the usage of odd eighths for higher-priced stocks, they are not significant for low-priced stocks.

\subsection{Size of Spreads}

Our analysis indicates that one might expect higher spreads for stocks avoiding odd eighths than for stocks using them regularly, controlling for other determinants of spreads. We look for an association between the frequency of odd eighths and the level of the spreads by regressing the time-weighted spread and the proportional timeweighted spread on the number of quotes in the period, the average time-weighted price, the standard deviation of price, and two dummy variables. The first dummy

\footnotetext{
${ }^{23}$ The average price is calculated as the average time-weighted price and similarly for the standard deviation of price.
} 
reflects avoidance of odd-eighths, taking the value of one if the proportion of time that the bid or ask is an odd multiple of $\frac{1}{8}$ is below $10 \%$. The second dummy reflects the stock price magnitude; it takes the value of one if the stock's average time-weighted price for the month is below $\$ 10$. Running these regressions, we find that the use of odd eighths is statistically significant. The results are in Appendix B.

The regression results indicate that avoidance of odd eighths increases the dollar spread by $\$ 0.21$ and the percentage spread by over $1 \%$ (the average percentage spread in the sample is between $2 \%$ and $3 \%$ ). ${ }^{24}$ Moreover, the odd-eighths avoidance dummy is much more significant than the price in explaining the spreads. In the time-weighted regression, price does not have any additional explanatory power. This is contrary to the findings of Huang and Stoll (1995), who employ a different estimation procedure and use a matched sample of Nasdaq and NYSE stocks for a different time period. Our finding also seem to be contrary to those of Laux (1995), who also employs a different methodology. Resolving this issue is left to future research.

\section{Conclusions and Policy Implications}

We show that the specifics of the Nasdaq regulatory environment affect theoretical conclusions based on models of Bertrand competition in potentially significant ways. While we do not have enough information to quantify the effect of these features on the range of equilibrium spreads, we do show that competition among a large number of Nasdaq market makers does not imply that spreads will be driven below the marginal cost of trading plus twice the tick size. Although the results are presented in the context of a very simple model, we argue that adding additional complexity to the model will reinforce the conclusion that competition in the Nasdaq markets need not drive prices down to marginal cost. In particular, allowing for preferenced trades and the impact of Nasdaq's Excess Spread Policy reinforces the results.

We also evaluate two proposed explanations for the phenomenon of the odd-

\footnotetext{
${ }^{24}$ We also ran these regressions on another sample, with alternative explanatory variables, and in logs. The results are quite robust.
} 
eighths avoidance documented by Christie and Schultz (1994) and provide an alternative explanation. The proposed explanation does not rule out the possibility of collusion, but shows that a simple focal-point equilibrium may allow market makers to attain profits similar to those possible with a formal collusive arrangement.

In our brief empirical analysis, we find that spreads increase as predicted with the avoidance of odd eighths. We also find evidence supporting our prediction that, due to differences in the tick size, low-priced stocks will not avoid odd eighths to the same extent that higher priced stocks will.

Since this paper discusses the impact of the regulatory features of Nasdaq, it seems natural to discuss policy implications. One point worth noting is that reducing the minimal tick size to $\frac{1}{16}$ (or even to $\$ 0.01$ ) would mean that price competition among market makers would force spreads below the level of costs plus approximately $\frac{1}{8}$, rather than costs plus approximately $\frac{1}{4}$. The reduction in distortions caused by the imposed price discreteness is likely to improve the efficiency of the market. 


\section{References}

Amihud, Yakov, and Haim Mendelson (1980), "Dealership Market: Market-Making with Inventory," Journal of Financial Economics, 8, 31-53.

Anshuman, V. Ravi and Avner Kalay (1994), "Market-Making Rents Under Discrete Prices," Working Paper, August.

Christie, William G. and Paul H. Schultz (1994), "Why do Nasdaq Market Makers Avoid Odd-Eighth Quotes?" The Journal of Finance, 49, 5, 1813-1840.

Christie, William G., Jeffrey H. Harris, and Paul H. Schultz (1994), "Why did Nasdaq Market Makers Stop Avoiding Odd-Eighth Quotes?" The Journal of Finance, 49, 5, 1841-1860.

Chan, K.C., William G. Christie, and Paul H. Schultz (1995), "Market Structure and the Intraday Pattern of Bid-Ask Spreads for Nasdaq Securities "Journal of Business, January, 68(1), 35-60

Copeland, Thomas E. and Dan Galai (1983), "Information Effects on the Bid-Ask Spread," The Journal of Finance, 38, 5, 1457-1469.

Demsetz, H. (1968), "The Cost of Transacting," Quarterly Journal of Economics 82, 33-53.

Dutta, Prajit K. and Ananth Madhavan (1994), "Competition and Collusion in Dealer Markets," Working Paper, March.

Easley, D. and M. O'Hara (1987), "Price, Trade Size and Information in Securities Markets," Journal of Financial Economics 19, 69-90.

Garman, Mark B. (1976), "Market Microstructure," Journal of Financial Economics 3, 257-275.

Glosten, Lawrence R. and Lawrence E. Harris (1988), "Estimating the Components of the Bid/Ask Spread," Journal of Financial Economics, 21, 123-142.

Glosten, Lawrence R. and Paul R. Milgrom (1985), "Bid, Ask and Transaction Prices in a Specialist Market with Heterogeneously Informed Traders," Journal of Financial Economics, 14, 71-100.

Godek, Paul (1995), "Why Nasdaq Market makers Avoid Odd Eighths Quotes", working paper, June 19. 
Grossman, Sanford J., Merton H. Miller, Daniel R. Fishel, Kenneth R. Cone and David J. Ross (1995), "Clustering and Competition in Asset Markets," a Lexecon Inc. Report, May 23.

Ho, Thomas and Hans R. Stoll (1981), "Optimal Dealer Pricing Under Transactions and Return Uncertainty," Journal of Financial Economics 9, 47-73.

Ho, Thomas and Hans R. Stoll (1983), "The Dynamics of Dealer Markets under Competition," Journal of Finance 38, 1053-75.

Huang, Roger D. and Hans R. Stoll (1994), "The Components of the Bid-Ask Spread: A General Approach," Working Paper 94-33, Owen Financial Markets Research Center, Vanderbilt University.

Huang, Roger D. and Hans R. Stoll (1995), "Dealer Versus Auction markets: A Paired Comparison of Execution Costs on Nasdaq and the NYSE," Working Paper 95-16, Owen Financial Markets Research Center, Vanderbilt University.

Kleidon, Allan W. and Robert D. Willig (1995), "Why Do Christie and Schultz Infer Collusion from their Data?", working paper presented at the Vanderbilt Conference.

Kothare, Meeta and Paul Laux (1995), "Trading Cost and the Trading Systems for Nasdaq Stocks," Financial Analysts Journal, March-April, 42-52.

Laux, Paul (1995), "The Bid-Ask Spread on Nasdaq Stocks that Quote on Even Eighths," Working Paper, August 21.

Madhavan, Ananth and Seymour Smidt (1993), "An Analysis of Changes in Specialist Inventories and Quotations," Journal of Finance 48, 1595-1628.

Nasdaq Fact Book and Company Directory (1994).

Stoll, H. (1978), "The Pricing of Dealer Security Services: An Empirical Study of NASDAQ stocks," Journal of Finance 33, 1153-1172.

Tirole, Jean (1988), The Theory of Industrial Organization, Cambridge, Mass.: MIT Press. 


\section{A Appendix - ESP}

The formulation of the ESP was tightened in July 1993. Table A1 presents the two versions. ${ }^{25}$

\begin{tabular}{|c|c|c|}
\hline $\begin{array}{c}\text { Average of Three } \\
\text { Smallest Spreads }\end{array}$ & $\begin{array}{c}\text { Maximum } \\
\text { Individual Spread } \\
\text { (Before 7/93) }\end{array}$ & $\begin{array}{c}\text { Maximum } \\
\text { Individual Spread } \\
\text { (After 7/93) }\end{array}$ \\
\hline$\frac{1}{8}$ or less & $\frac{1}{4}$ & $\frac{1}{4}$ \\
\hline$\frac{1}{4}$ & $\frac{1}{2}$ & $\frac{3}{8}$ \\
\hline$\frac{3}{8}$ & $\frac{3}{4}$ & $\frac{1}{2}$ \\
\hline$\frac{1}{2}$ & 1 & $\frac{5}{8}$ \\
\hline$\frac{5}{8}$ & 1 & 1 \\
\hline$\frac{3}{4}$ & $1 \frac{1}{2}$ & 1 \\
\hline$\frac{7}{8}$ & $1 \frac{1}{2}$ & $1 \frac{1}{8}$ \\
\hline 1 & $1 \frac{1}{2}$ & $1 \frac{1}{4}$ \\
\hline
\end{tabular}

Table A1

The implications of the ESP are the most stark when market makers avoid odd eighths and the penalty for violation is sufficiently large that no market maker is willing to violate the ESP. For this case, we can calculate how the average of the three smallest spreads might evolve over time. Denote the bid price of the $j^{\text {th }}$ market maker in period $t$ by $b_{t}^{j}$ and denote the ask price of the $j^{t h}$ market maker in period $t$ by $a_{t}^{j}$. Define $s_{t}$ to be the average of the spreads of the three market makers posting the smallest spreads in period $t$. Then:

\begin{tabular}{|l|l|l|l|l|l|l|l|l|}
\hline$s_{0}=0.75$ & $\Rightarrow$ & $a_{1}^{i}-b_{1}^{i} \leq 1$ & $\Rightarrow$ & $s_{1} \leq 1$ & $\Rightarrow$ & $a_{2}^{i}-b_{2}^{i} \leq 1.25$ & $\Rightarrow$ & $s_{2} \leq 1.25$ \\
\hline$s_{0}=0.5$ & $\Rightarrow$ & $a_{1}^{i}-b_{1}^{i} \leq 0.5$ & $\Rightarrow$ & $s_{1} \leq 0.5$ & $\Rightarrow$ & $a_{2}^{i}-b_{2}^{i} \leq 0.5$ & $\Rightarrow$ & $s_{2} \leq 0.5$ \\
\hline$s_{0}=0.25$ & $\Rightarrow$ & $a_{1}^{i}-b_{1}^{i} \leq 0.25$ & $\Rightarrow$ & $s_{1} \leq 0.25$ & $\Rightarrow$ & $a_{2}^{i}-b_{2}^{i} \leq 0.25$ & $\Rightarrow$ & $s_{2} \leq 0.25$. \\
\hline
\end{tabular}

Table A2

The arrows indicate that a particular value of the initial average spread implies limits on the individual spread in the next period, which in turn determines the range in which the average spread must lie. One can see that once three market makers use individual spreads of $\frac{1}{2}$ or $\frac{1}{4}$, spreads can never increase above those values in the future.

${ }^{25}$ This table is taken from the "NASD Notice to Members," 93-43, July 1993. 


\section{B Appendix - Regression Results}

\section{B.1 Avoidance of Odd Eighths}

The dependent variable is the average of the proportion of time the ask quotes are an odd multiple of $\frac{1}{8}$ and the proportion of time the bid quotes are an odd multiple of $\frac{1}{8}$. The resulting variable is referred to as the proportion of odd-eighths usage. The following independent variables are used in the regression: NUMQ - number of quote updates (divided by 100) for a stock during the month, which seems to provide a better measure of the stock's activity than the volume; AVPRICTW - average time-weighted price of the stock during the month; and STDPRICTW - standard deviation of the time-weighted price. The regression is run separately on two subsamples, low-priced $(<\$ 10)$ and high-priced stocks $(>\$ 10)$, to allow for different functional forms for stocks with different ticks sizes. ${ }^{26}$ The results are reported in the Table B1 (standard errors are in parentheses). ${ }^{27}$

\begin{tabular}{|c|c|c|c|c|c|}
\hline \multicolumn{7}{|c|}{ Time-weighted Prices } \\
\hline Sample (\# obs) & Intercept & NUMQ & AVPRICTW & STDPRICTW & $\mathbf{R}^{2}$ \\
\hline Prices <\$10 (31) & 1.06 & 0.003 & -0.039 & -2.61 & 0.44 \\
\hline & $(0.33)$ & $(0.016)$ & $(0.035)$ & $(0.82)$ & \\
\hline Prices $>\$ 10(324)$ & 0.34 & 0.055 & -0.011 & -0.08 & 0.26 \\
\hline & $(0.04)$ & $(0.01)$ & $(0.002)$ & $(0.166)$ & \\
\hline
\end{tabular}

Table B1

\section{B.2 Size of Spreads}

We regress the dollar and percentage spreads on the number of quotes (divided by 100), NUMQ, the average time-weighted price of the stock during the month, AVPRICTW, the standard deviation of that price, STDPRICTW, and two dummy variables. The odd-eighths avoidance dummy, DUMODD8, takes the value of one if the proportion of time the inside quotes include an odd multiple of $\frac{1}{8}$ is below $10 \%$ and is zero otherwise. The small price stock dummy, DUMSMPR, takes the value of one if the stock's average time-weighted price during

\footnotetext{
${ }^{26}$ Some stocks only have a tick size of $\frac{1}{16}$ for part of the month. If we define low-priced stocks as those with an average price below $\$ 10$, then these stocks are included with the high-priced stocks. If anything, this should bias the results against our hypotheses.

${ }^{27}$ We have tried using other possible independent variables, and the results remain essentially the same.
} 
the month is below $\$ 10$ and is zero otherwise. The coefficient on this is not significant and is not presented. The results are presented in Table B2 (standard errors are in the parentheses).

\begin{tabular}{|c|c|c|c|c|c|c|}
\hline Dep. Var. & Intercept & NUMQ & AVPRICTW & STDPRICTW & DUMODD8 & $\mathbf{R}^{2}$ \\
\hline Time-weighted & 0.20 & 0.0002 & -0.0014 & 0.47 & 0.215 & 0.67 \\
\hline dollar spread & $(0.02)$ & $(0.005)$ & $(0.0012)$ & $(0.08)$ & $(0.014)$ & \\
\hline Time-weighted & 0.031 & -0.0004 & -0.0009 & 0.01 & 0.011 & 0.63 \\
\hline \% spread & $(0.001)$ & $(0.0003)$ & $(0.00007)$ & $(0.005)$ & $(0.0008)$ & \\
\hline
\end{tabular}

Table B2 